\title{
PERSEO EN EL ROMANCERO CLÁSICO: LAS ROSAS DE ROMANCES DE JUAN DE TIMONEDA
}

\author{
ESTHER FERNÁNDEZ LÓPEZ \\ UNED \\ fernandezlopezesther@gmail.com
}

\section{RESUMEN}

El presente trabajo se plantea como un análisis de tres poemas sobre el mito de Perseo recogidos en las Rosas de Romances del valenciano Juan de Timoneda (1573). Creemos que se trata de los primeros textos de la Literatura Española que abordan este mito, anteriores en quince años al romance sobre Perseo y Andrómeda de Juan de la Cueva (1588). Nuestro estudio muestra la dependencia de los romances de Timoneda respecto a la traducción de las Metamorfosis de Ovidio llevada a cabo por Jorge de Bustamante en la primera mitad de esa misma centuria, y a su vez un afán de suprimir algunos episodios claves de la fábula para constituir un todo más cercano al mundo caballeresco.

Palabras Clave: Perseo en la Literatura Española; romances; Timoneda; Metamorfosis de Ovidio; traducción de Bustamante.

\section{ABSTRACT}

Ce travail est présenté comme une analyse de trois poèmes sur le mythe de Persée recueillis dans les Roses de Romances du Valencien Juan de Timoneda (1573). Nous croyons qu'il s'agit des premiers textes de la littérature espagnole traitant de ce mythe, antérieures en quinze ans à la romance sur Persée et Andrómeda de Juan de la Cueva (1588). Notre étude montre la dépendance des romances de Timoneda concernant la traduction des Métamorphoses d'Ovide menée par Jorge de Bustamante dans la première moitié du même siècle, et en même temps un désir de supprimer certains épisodes clés de la fable pour constituer un ensemble plus près du monde chevaleresque.

Mots CLÉs: Persée dans la littérature espagnole; romances; Timoneda; Métamorphoses d'Ovide; traduction de Bustamante. 
La fascinación que el mundo clásico ejerció en los ambientes cultos de la Europa medieval queda reflejada en la proliferación de obras artísticas que abordan las diversas fábulas de la mitología grecolatina, conocidas básicamente a través de las Metamorfosis ovidianas. El poeta de Sulmona fue conocido y venerado por todos los autores cultos, ya directamente en el texto original latino o bien (con mayor frecuencia) a través de fuentes indirectas. En España, la publicación de diversas versiones castellanas del poema de Ovidio a partir del siglo XVI supuso un enorme impulso para la difusión de las fábulas paganas ${ }^{1}$, si bien existía ya el antecedente de la obra de Alfonso X, en el siglo XIII².

${ }^{1}$ La primera traducción de las Metamorfosis que se imprimió en España fue la catalana de Francesch Alegre (Lo llibre de les transformacions del poeta Ovidi, Barcelona, 1494, aunque realizada hacia 1480). Sin embargo, existió otra versión anterior, también al catalán, debida a Francisco de Pinós y que hoy se ha perdido (Bescos Prat, Pere (2007): Humanisme i traducció catalana durant la segona meitar del segle XV: Ferran Valentí, Arnau d'Alfarràs, Francesc Alegre i Aleix de Barcelona, Barcelona, Universitat Pompeu Fabra, p. 25. http://repositori.upf.edu/ bitstream/handle/10230/1268/PereBescos.pdf?sequence=1).Habría que esperar hasta la primera mitad del XVI para encontrar la primera de las cuatro versiones castellanas que aparecieron en esa centuria, debida al humanista cántabro Jorge de Bustamante (la editio princeps apareció sin fecha ni lugar de edición). Compuesta en prosa, al igual que sus predecesoras catalanas, esta traducción sería, con mucho, la que gozara de mayor difusión. Se trata de una versión libre del poema ovidiano, al que se añaden diversos elementos procedentes de otras fuentes. El trabajo de Bustamante constituye la única de las traducciones áureas a nuestra lengua que se vio libre del influjo de las italianas de Ludovico Dolce y de Giovanni Andrea dell'Anguilara. Con posterioridad aparecerían otras tres versiones castellanas, todas ellas en verso (como sus modelos italianos): la de Antonio Pérez Sigler (1580), la de Felipe Mey, que se limita a los siete primeros libros (Tarragona, 1586) y la de Pedro Sánchez de Viana (1589).

${ }^{2}$ En efecto, la General Estoria de Alfonso X, junto con la Estoria de España (o Primera Crónica General), constituye una de las dos magnas obras historiográficas en las que el Rey Sabio pretendía dar cuenta de todos los hechos acaecidos (respectivamente, en el mundo conocido y en la Península Ibérica) desde la Creación hasta su época. A tal fin, el recopilador alfonsí se basará en cuantas fuentes caigan en sus manos: no solo las obras propiamente históricas (como las de Pedro Coméstor o Paulo Orosio), sino también los relatos mitológicos y, por supuesto, las Sagradas Escrituras. En una línea similar, ya en el siglo xv, encontramos el tratado Sobre Eusebio de Alonso Fernández de Madrigal, llamado El Tostado (o, también, el abulense). Se trata de un extensísimo trabajo en seis volúmenes compuesto a mediados de la citada centuria por encargo del Marqués de Santillana. Madrigal expone exhaustivos comentarios a la Crónica Universal o Libro de los tiempos, escrito en griego por Eusebio de Cesarea en el siglo IV y traducido al latín por San Jerónimo en la centuria siguiente. Dicha obra partía de la explicación evemerista de la mitología pagana para elaborar una historia sincrónica de la humanidad que tomara como eje la del pueblo de Israel. De este modo, las tablas cronológicas de Eusebio pretendían incluir los mitos clásicos como acontecimientos realmente acaecidos en algún momento de la Historia, confiriéndoles así un cariz de autenticidad autorizada por el hilo de los hechos narrados en la Biblia. Tanto el Rey Sabio como el Tostado parten de esos supuestos, si bien incluyen igualmente en sus respectivas obras la interpretaciones alegóricas que tanto predicamento alcanzaron desde la Edad Media. Este último enfoque será el eje central de otra obra sobre mitología aparecida por la misma época e igualmente por encargo de López de Mendoza. Se trata de los Morales de Ovidio, traducción llevada a cabo por Alonso de Zamora del Ovidius Moralizatus. Esta última obra (que tuvo una gran repercusión entre los tratadistas de la Europa medieval) constituye una suerte de apéndice del Reductorium morale, volumen compuesto en el siglo XIV por el benedictino francés Pierre Berçuire e integrado en su parte principal por quince libros que desarrollan una serie de comentarios a las Escrituras. Según apunta Derek C. Carr, este trabajo de Alonso de Zamora se correspondería con la traducción del Libro mayor de las Transformaciones de Ovidio (como se conocía en la época a las Metamorfosis) que el Marqués se ufana de haber ordenado, como le escribe en una célebre carta a a su hijo don Pedro González de Mendoza - el futuro Cardenal— (Carr, Derek C (2005), «El lenguaje y el léxico de los Morales de Ovidio [BN, ms. 10144]: unas observaciones preliminares», en Piñero Ramírez, Pedro M: Dejar hablar a los clásicos: homenaje a Francisco Márquez, Villanueva. Sevilla, Universidad, pp. 193-202. https://books.google.es/books?id=DHgEvHBDNBkC\&pg=PA193\&lpg=PA193\&dq=morales+ovidio). No obstante, algunos autores consideran que en la citada carta, Santillana alude en realidad a otra supuesta traducción del poema ovidiano, que constituiría una de las obras perdidas 
Una de las historias mitológicas que gozaron de mayor popularidad en las letras españolas desde bien temprano es la de Perseo. Y es que, como bien señaló Kirk ${ }^{3}$, los hechos relacionados con este héroe entroncan fácilmente con diversos motivos propios del cuento tradicional: orígenes míticos, hazañas notables, uso de objetos mágicos, intervención de seres sobrenaturales o monstruosos, matrimonio con una bella princesa... Muchos de nuestros autores se hicieron eco de esta popularidad adaptando en sus obras mayores y menores las aventuras del héroe de Argos. Como ocurrió con los demás mitos clásicos, también el que aquí nos ocupa se plasmó, sobre todo, en el teatro y en la poesía. Entre las piezas dramáticas que recogieron el mito destacan las comedias de Lope $^{4}$ y Calderón ${ }^{5}$ y el auto sacramental de este último ${ }^{6}$. En cuanto a las composiciones poéticas, dos son los cauces básicos para recoger estas historias de la Antigüedad grecolatina: la fábula mitológica y el soneto (el propio Lope compuso también una obra perteneciente al primero de estos géne$\operatorname{ros}^{7}$, así como varios sonetos sobre la escena de la liberación de Andrómeda). No obstante, también el género romancístico daría pie a la recreación de los mitos paganos, y entre ellos el de Perseo.

En su estudio ya clásico sobre las Fábulas mitológicas en España, don José María de Cossío distingue entre dos tipos de romances sobre tema mitológico que proliferan en nuestra literatura del siglo Xvi: los de tradición oral y los romances historiales ${ }^{8}$. Como observa Marichu Cruz de Castro, si los mitos grecolatinos se introdujeron con total normalidad en un género poético tan genuinamente popular como el romance, «no cabe duda de que el conocimiento de la Antigüedad Clásica ni se ciñó al habitáculo de los estudiosos ni careció de una notable difusión en el seno de la Edad Media»?

El siglo XVI fue una época de esplendor del romancero y de su transmisión oral y escrita. En palabras de esta misma investigadora, «el pueblo cantaba y transformaba los romances

de la biblioteca del Marqués. Es el caso, por ejemplo, de Antonio Antelo Iglesias, quien apunta como posibles causas de tal pérdida el incendio que sufrió el palacio familiar de los Mendoza en 1702, o bien la orden de vender un centenar de libros que hace Santillana, en su testamento, para saldar sus deudas (Antelo Iglesias, Ángelo (1991): «Las bibliotecas del otoño medieval. Con especial referencia a las de Castilla en el siglo XV», en Espacio, tiempo y forma, S III, $H^{a}$ Medieval, t. 4, pp. 285-350 http://dialnet.unirioja.es/servlet/autor?codigo=103254). Por lo demás, parece ser que esta versión moralizada de las Metamorfosis tuvo una repercusión más bien escasa, e incluso lo más probable es que se limitara al uso personal de López de Mendoza. Por su parte, la magna obra del Tostado permaneció en el olvido hasta que el Cardenal Cisneros se interesó por la publicación de las obras completas del abulense (labor que se realizó entre 1507 y 1531), y aun así tampoco gozó de una gran difusión posterior. De ahí que podamos considerar la General Estoria alfonsí como el único material en castellano que pudiera haber sido conocido como transmisor de los mitos grecolatinos hasta la aparición de la traducción del poema ovidiano por Bustamante.

${ }^{3}$ Kirk, G. S. (1973): El mito: significado y funciones en las distintas culturas, Barcelona, Barral editores.

${ }^{4}$ Vega Carpio, Lope de: La fábula de Perseo o La bella Andrómeda (1621). Esta pieza es más conocida popularmente como El Perseo.

5 Calderón de la Barca, Pedro: Las fortunas de Andrómeda y Perseo (1653).

${ }^{6}$ Calderón de la Barca, Pedro: Andrómeda y Perseo (1680).

7 Se trata de la fábula mitológica La Andrómeda, incluida en Vega Carpio, Lope de: La Filomena (1621).

${ }^{8}$ Cossío, José M. a de (1998): Fábulas mitológicas en España (2 vols.), reedición, Madrid, Istmo [el estudio original se publicó por primera vez en 1952]; pp. 140 y ss. https://books.google.es/books?id=qmNFGjNCa64C\&printsec=frontcover\&dq=inauthor:"José+María+de+Cossío"

${ }^{9}$ Cruz de Castro, Marichu (1993): Romances de la Antigüedad Clásica, Madrid, Ediciones Clásicas. Col. Ruta de la Memoria (dirigida por Vicente Cristóbal). «Nota Preliminar», pp. 1-15 [p. 1]. 
creados por el juglar, los eruditos escribían otros nuevos y los editores imprimían y reimprimían sin parar pliegos sueltos y romanceros» ${ }^{10}$. Las primeras compilaciones de estos pliegos aparecen a mediados de la centuria, y en ellos encontramos por doquier romances basados en relatos mitológicos clásicos. Señala Vicente Cristóbal cómo este tipo de romances

narran unidades míticas completas, pero con cierta abreviación con respecto a sus fuentes. Muchos de ellos derivan de las Metamorfosis, aunque casi siempre a través de la traducción de Bustamante o de fábulas mitológicas cultas, resumiéndolas y adaptándolas a un tono de menos altura. Determinadas colecciones como el Cancionero de romances de Amberes, el Cancionero General de Hernando del Castillo (1557), la compilación de Lorenzo de Sepúlveda (1551), la Rosa de romances de Juan de Timoneda (1573), la Flor de Enamorados de Juan de Linares (1575), el Romancero historiado de Lucas Rodríguez (1585) y El Coro Febeo de Juan de la Cueva (1588) tienen abundantes ejemplos de este género, aparte de los que se han conservado en la tradición oral española, americana y sefardí. Tereo, Progne y Filomela (transformados los dos primeros en Turquillo y Blanca Flor y Filomena), Sálmacis, juicio de Paris, muerte de Adonis, Jasón y Medea, Píramo y Tisbe, Céfalo y Procris, Perseo y Andrómeda, Ariadna y Teseo, son algunos de los temas que, claramente, derivados de las Metamorfosis, reciben tratamiento romancístico ${ }^{11}$.

En cuanto a los llamados «romances historiales», señala Cossío que se trata de un género de carácter semipopular, por cuanto

sus autores se proponen comunicar los temas poéticos al pueblo y buscan para ello una expresión popular que, en casos, les aproxima a los aciertos de la poesía tradicional; pero los temas, y los descuidos de la ejecución, cada uno por su parte, les denuncian como poetas cultos que quieren contrahacer las formas populares y poner su verso a la altura de los humildes ignorantes. ${ }^{12}$

El término «historiales» procede de uno de estos autores: Juan de la Cueva, quien lo incluye en el título de su obra Coro Febeo de romances historiales (Sevilla, 1588). En las páginas iniciales, el poeta explica la finalidad didáctica de las composiciones recogidas en el volumen:

$$
\begin{aligned}
& \text { Los romances son compedio } \\
& \text { y abreviación de lo escrito } \\
& \text { de las antiguas historias, } \\
& \text { y por ellos han vivido } \\
& \text { muchas, que tienen hoy vida, } \\
& \text { que se hubieran ya perdido. } \\
& \text { Los romances comprehenden } \\
& \text { en su humilde y llano estilo } \\
& \text { todas cuantas cosas quieren }
\end{aligned}
$$

\footnotetext{
${ }^{10}$ Ibídem, pp. 7-8.

11 Cristóbal López, Vicente (1997): «Las Metamorfosis de Ovidio en la literatura española. Visión panorámica de su influencia con especial atención a la Edad Media y a los siglos XVI y XVII». Cuadernos de Literatura griega y latina, I. Delegación de Galicia. Santiago de Compostela, pp. 125-153 [p. 134-135].

${ }^{12}$ Cossío, op. cit., p. 140.
} 
cantar, de virtud o vicios,

empresas del fiero Marte,

de amor ardientes suspiros,

quejas, celos, burlas, veras,

lealtades, tratos fingidos,

aficiones y ficiones,

y otros casos sucedidos,

cual se verán largamente

tratados en ese libro. ${ }^{13}$

Señala Cossío cómo el mayor interés de este género romancístico es el de difundir abundantes fábulas mitológicas - muchas de ellas tratadas por primera vez en este tipo de poesía-y, con ello, preparar el terreno «para empresas de más alto bordo» ${ }^{14}$.

Es precisamente en el citado libro de Juan de la Cueva donde encontramos un extenso Romance de Andrómeda y cómo Perseo la libró de la muerte y lo que sucedió más. Cossío cita esta composición como el primer intento español de adaptar literariamente la historia de nuestro héroe. Sin embargo, este dato no es exacto: con una anterioridad de más de una década aparecen publicados otros tres textos romancísticos que abordan diversos episodios del mito, y que pertenecen al romancero clásico de tradición oral, tal y como apuntaba Vicente Cristóbal.

En efecto, de 1573 data la colección romancística donde encontramos estos poemas que, pensamos, serían los primeros en abordar la historia de Perseo. Se trata de las Rosas de romances del polifacético valenciano Juan (o Joan) de Timoneda (ca. 1520-1583): actor y dramaturgo, librero y editor, traductor y poeta, compilador y refundidor de cuentos y romances.

Timoneda distribuye el citado volumen en cuatro series o libros: Rosa de amores, que recoge poemas de carácter sentimental; Rosa española, histórico-líricos; Rosa gentil, romanos y troyanos; y Rosa real, principescos. Se trata, según Cruz de Castro, de «una amalgama de romances viejos, nuevos y otros del mismo Timoneda» ${ }^{15}$. Por desgracia, debemos tomar en consideración la siguiente advertencia de Valentino Bompiani:

Téngase en cuenta a efectos de diferenciar en ediciones conjuntas, v. gr. las poéticas, la obra propia de la ajena, la dificultad que supone la costumbre de T. de no especificarlo en sus publicaciones. Igualmente difícil resulta discernir las meras traducciones y ediciones de las adaptaciones y propias creaciones. ${ }^{16}$

${ }^{13}$ Versos citados por Cossío, op. cit., pp. 140-141.

${ }^{14}$ Cossío, ibídem, p. 142.

${ }^{15}$ Cruz de Castro, Marichu, loc. cit., p. 13. Este volumen recopilatorio recoge entre otros los tres romances que analizamos en el presente trabajo.

${ }_{16}$ Bompiani, Valentino (1992): Diccionario de autores de todos los tiempos y de todos los países (5 vols.), Barcelona, Ed. Hora, $4^{\text {a }}$ ed. Vol. V (1 ${ }^{\text {a }}$ ed. en español: Montaner \& Simón, S. A, 1963 (es trad. del italiano Dizionario degli autori) p. 2758. 
En efecto, poco o nada nos aclara a este respecto la «Epístola al lector» con la que Timoneda encabeza amablemente el volumen:

Discreto lector de ver infinitissimos Romances proprios mios antiguamente trobados, y agora de nueuo perdidos que no se hallauan, con algunos modernos, me fue forçado a disponerme de hazer recogimiento dellos, y por ser tantos, diuidillos en quatro Partes, dandoles el competente lugar que merescen. Verdad es que por dos causas me huue de allegar a algunos Romances viejos. La vna, por dar perfeccion a las Hystorias acometidas. La otra, por hazer verdadero aquel Refran que dize. Allegate a buenos, y seras uno dellos. ${ }^{17}$

Así las cosas, ignoramos si Timoneda es o no el creador de las tres composiciones a la que venimos refiriéndonos. No obstante, la hipótesis más probable es que se trate de anónimos poemas pertenecientes al viejo romancero clásico a los que el valenciano se habría «allegado» para dar prestancia a su compilación.

Estos romances relatan sucesivamente diversos episodios de la historia y constituyen así una suerte de ciclo que, en total, apenas comprende ciento cuarenta versos. Una peculiaridad formal común a los tres poemas es el empleo de la rima consonante, si bien se trata de rima fácil en todos los casos. Por lo demás, esta es la tónica general de los textos recopilados en el volumen de Timoneda (si bien tampoco faltan en él los romances asonantados).

La primera de estas piezas es el Romance de Dánae. Se trata del más breve de los tres poemas, con treinta y dos octosílabos que en los pares riman en -áda. Salvo en los vv. 16 y 28 (que se cierran, respectivamente, con las voces «almohada» y «nada»), los términos que dan pie a la rima son participios femeninos.

A este primer texto sigue el Romance de Perseo, que ocupa una cincuentena de versos. En este caso el consonante es en -ádo, y buena parte de las voces en rima son participios masculinos ${ }^{18}$. Como curiosidad métrica encontramos la acentuación paroxítona del nombre de Dánae en el v. 1 y su forzamiento en sinéresis en el v. 45, mientras que, en las otras dos ocasiones en que aparece el nombre (vv. 19 y 39), su pronunciación resulta indiferente a efectos métricos. Cabe, asimismo, reseñar un caso de hiato o dialefa en el v. 31 («te apiades que no muera») y una rima más que fácil, al tratarse de la misma palabra («doblado») ${ }^{19}$ en dos versos pares sucesivos (22 y 24).

17 Timoneda, Juan de (1963): Rosas de romances. Ed. (facsímil de la de 1573) de Daniel Devoto y A. Rodríguez-Moñino, Valencia, Castalia, p. 1. En realidad, ni siquiera queda claro si esta ambigua declaración sobre la autoría de los romances editados se refiere a la totalidad de los textos recogidos en el volumen o solo a la primera de sus partes; pues cada una de las otras tres va a su vez encabezada por una advertencia al lector. Además, por lo que se refiere a la Rosa Real, Timoneda afirma tajantemente ser el autor de todas las piezas y se jacta de ello, subrayando el hecho con la constatación en cada uno de los romances de la fecha en que tuvo lugar el acontecimiento que dio pie a su composición. Por otro lado, la Rosa de Amores, primera parte del volumen, lleva un Explícit que indica que se acabó de imprimir en 1572, un año antes que las otras Rosas.

${ }_{18} \mathrm{Y}$ aun las otras son igualmente participios que han sufrido traslación a otras categorías: bien a la nominal («cuidado», v. 2; «preñado», v. 4, en sentido de 'preñez’) bien a la adjetival («honrado», v. 6; «airado», v. 8).

19 McGaha denomina «autorrima» a este fenómeno (en sus «Notas explicativas», de Vega Carpio, Lope (1985): La fábula de Perseo o la bella Andrómeda. Ed. crítica, introducción y notas de Michael D. Mc. Gaha, Kassel Edition Reichenberger, passim). https://books.google.es/books?id=KZxof2oxbmUC\&pg=PA34\&lpg=PA34\&dq=lope+mcgaha+perseo\&source 
El ciclo que Timoneda dedica a nuestro mito se cierra con el Romance de Andrómeda, que narra el rescate de esta por Perseo. Se trata del más extenso de los tres poemas, con cincuenta y ocho octosílabos, y es también el único que presenta rima oxítona o «masculina». De nuevo, la rima es consonante, y en este caso está constituida por la terminación -ar, que en casi todos los versos corresponde a otros tantos infinitivos; solo en los vv. 4 («par»), 6 («mar») y 40 pertenecen a la categoría nominal las voces que dan pie a la rima, y aun en este último caso («a mi pesar») se trata de la sustantivación de un infinitivo. Métricamente destaca también aquí la transformación en paroxítono de un nombre propio esdrújulo, en este caso el de Calíope en las dos ocasiones en que aparece (vv. 3 y 29).

Pero lo más llamativo de todo en los tres romances que nos ocupan es lo que tiene que ver con su contenido. En efecto, los dos primeros textos se centran en la peripecia de Dánae y nos presentan sucesivamente las circunstancias de su encierro y embarazo, el nacimiento de Perseo y el abandono en el arca por parte de Acrisio (Romance de Dánae); y la llegada a Acaya y rescate del arca por Polidetes, que se hará cargo de sus dos ocupantes (Romance de Perseo). El tercero de los poemas, en cambio (Romance de Andrómeda), nos narra directamente la liberación de la princesa por Perseo, ya adulto. Faltan, por tanto, los episodios de Medusa y de Atlas, fundamentales (especialmente el primero) en relación con las hazañas del héroe. Por lo demás, tampoco se dice nada de los sucesos posteriores al rescate de Andrómeda.

Una primera hipótesis explicativa podría llevarnos a suponer que Timoneda está recopilando romances (propios o ajenos) y estableciendo una selección de textos que podrían haber dejado fuera algún otro romance que tratase los episodios de Medusa y de Atlas, e incluso de los sucesos posteriores a las bodas entre Perseo y Andrómeda. O bien cabría una segunda posibilidad: la de que tales romances, de haber existido, no hubieran llegado a las manos del librero valenciano.

Sin embargo, como veremos más adelante, el análisis de los tres romances demuestra que el autor parece haber omitido deliberadamente los dos episodios mencionados. En este sentido podemos traer a colación las siguientes palabras de Cruz de Castro:

Respecto a la elaboración romancística de los mitos provenientes de las Metamorfosis, observamos que las transformaciones relatadas por Ovidio se producen en el romance cuando es preciso partir de ellas para contar el mito [...] y que suelen suprimirse cuando ocurren al final de la ficción. ${ }^{20}$

Sin embargo, esto no resulta exacto en el caso que nos ocupa. Cierto es que el romancista toma como punto de partida precisamente la transformación de Júpiter en lluvia de oro para seducir a Dánae (uno de los furta Iovis más notables de la mitología clásica), lo que dará lugar a la concepción de Perseo. Sin embargo, los dos episodios omitidos no se sitúan originalmente al final del relato: lejos de eso, la obviada decapitación de Medusa no solo no consiste en una transformación, sino que de hecho constituye la primera de las

\footnotetext{
${ }^{20}$ Cruz de Castro, Marichu, loc. cit., p. 6.
} 
hazañas del héroe y el motor de casi todas las ulteriores ${ }^{21}$. Por su parte, la petrificación de Atlas (que sí que supone una transformación) es subsidiaria de esa primera hazaña de Perseo y, a su vez, se presenta como la primera ocasión en la que el héroe utiliza la cabeza de la gorgona como arma mortal. Curiosamente, todos los episodios posteriores en los que Perseo hace uso del mismo recurso para vencer a sus enemigos aparecen igualmente omitidos en los romances que nos ocupan.

Pero tampoco podemos achacar la ausencia de estos episodios (como vemos, decisivos en la historia de Perseo) a la fuente utilizada por el autor. Pues, como comprobaremos enseguida, esta fuente no es otra que la versión en prosa de las Metamorfosis llevada a cabo por Jorge de Bustamante en el siglo Xv.

\section{Señala Cruz de Castro que}

a veces [...] un romance se ciñe fielmente al relato de Ovidio y entonces hay que concluir que el romancista dispuso del original, o bien —en el caso de textos tardíos- de la traducción de las Metamorfosis hecha por Bustamante en 1545 y conocida por todos los poetas de la época. ${ }^{22}$

Dejando aparte la fecha de edición — que sigue siendo una quaestio disputata-, en el caso de los tres romances que aquí abordamos esta fidelidad resulta quasi absoluta en la mayor parte del texto, hasta el punto de que podemos hablar de verdadera dependencia más que de fidelidad. Sin embargo, como venimos observando, en otros pasajes -y singularmente en los relacionados con la la cabeza de Medusa-, tal fidelidad desaparece por completo (como también desaparece el texto mismo). Así se podrá apreciar si comparamos cada uno de los poemas con el pasaje correspondiente de dicha traducción ${ }^{23}$.

Para comprobarlo, observemos en primer lugar el texto del Romance de Dánae, colocado en una tabla comparativa junto al fragmento correspondiente de la traducción ovidiana (en este último hemos señalado en cursiva los pasajes coincidentes):

${ }^{21}$ En lo que se refiere a la lucha con el monstruo marino, Ovidio no menciona el uso de la cabeza de Medusa como arma auxiliar (como aparecerá en diversas recreaciones posteriores del mito), sino que Perseo le da muerte utilizando exclusivamente su espada o cimitarra.

22 Cruz de Castro, Marichu, loc. cit., p. 2.

${ }^{23}$ Los textos romancísticos están tomados de la edición de Cruz de Castro (pp. 28-33), donde figuran respectivamente con los números 6, 7 y 8; aunque también se ha consultado la edición facsímil de 1963 llevada a cabo por Devoto/ Rodríguez Moñino (Vid. nuestra n.17). Por su parte, los fragmentos de la traducción de Bustamante proceden de la primera edición (Libro del Metamorphoseos y fabulas del excelente poeta Ouidio noble cauallero Patricio romano: traduzido de latin en romance). En ella no constan ni la fecha ni el lugar de edición, mientras que el nombre del autor aparece en unos versos acrósticos preliminares que nos revelan que era «natural de Silyos» (se trata de una pequeña localidad de Cantabria). El ejemplar que manejamos se conserva en la Biblioteca Nacional (signatura R. 32190). Hemos utilizado también un ejemplar de la edición de 1664 publicada «en Madrid: por Domingo Morras: a costa de Antonio del Ribero Rodríguez» bajo el título de Las Metamorfosis o Transformaciones de Ovidio en quinze libros: buelto en castellano (el ejemplar procede de la Blblioteca Histórica de la Universidad de Valencia, y lleva la signatura G-0403). Tampoco en este caso hay constancia del nombre del autor más allá de los versos acrósticos. 


\section{ROMANCE DE DANAE}

Acricio, viendo a su hija

Dánae tan agraciada, en una torre la puso para estar mejor guardada.

5 Júpiter, enamorado de su lindeza extremada, convirtióse en grano de oro y en lluvia muy moderada: sobre las haldas de Dánae cayó estando descuidada. Ella, cogiéndolos todos, alegre y regocijada, púsoselos en los pechos en su cámara encerrada; sacólos todos y, puestos encima de una almohada, Júpiter volvióse entonces en su figura formada; Dánae de ver aquesto cayó en tierra desmayada; Júpiter con sus regalos, ya que la hubo consolada, junto durmiera con ella; de aquella vez fue preñada, $\mathrm{y}$ antes que Febo hubiese su luz al mundo mostrada, a Dánae dejó durmiendo, fuese sin decirle nada. La ya hecha dueña triste quedó, muy atribulada, más porque Júpiter fue quien tan mal la había burlada.

\section{VERSIÓN DE BUSTAMANTE}

Acrisio viendo la estremada hermosura de Danae su hija, y temiendo que no peligrasse su virginidad la encerro en vna torre, donde la hazia guardar con gran vigilancia. Sabiendo esto Jupiter estando muy enamorado desta donzella para cumplir conella su deseo baxo desde el cielo dexada toda su majestad; y pusose sobre esta torre y porvn resquicio o resquebradura della tornado lluuia ogranos de oro se dexo caer enlas faldas de Danae; y alli tornado en su figura dormio conella, y la dexo preñada de Perseo; y hecho esto se torno al cielo. La ya hecha dueña quedo muy triste desta burla $[\ldots]$

Como podemos apreciar, entre uno y otro textos se dan evidentes concomitancias, pues en ambos encontramos expresiones que son idénticas o que lo son prácticamente (y que, por lo demás, poco tienen de hallazgos expresivos, pues más bien se trata de voces y estructuras sencillas y corrientes). Podemos suponer que el autor de este romance (sea o no Timoneda) tiene delante al componerlo la versión ovidiana de Bustamante, hasta el punto de que por momentos no parece sino que el romancista pretende directamente versificar el texto de la traducción.

Pero las similitudes entre el Romance de Dánae y el fragmento de Bustamante no se agotan en la literalidad textual: al contrario, encontramos, además, otras coincidencias relacionadas con el contenido. 
En este sentido, obsevamos en primer lugar que ninguno de los dos textos hace alusión al oráculo que vaticinaba que Acrisio moriría a manos de un hijo de Dánae (vaticinio que constituye la causa del encierro de la muchacha). En lugar de eso, tanto Bustamante como Timoneda achacan este encierro a un recelo de Acrisio por la honra de su hija. El hecho es señalado por Cruz de Castro, quien observa - refiriéndose al «romancista»— que «de este modo acerca el mito a la moral de la época ${ }^{24}$. Sin embargo, lo cierto es que el intento de preservar la virginidad de Dánae como motivo de su confinamiento se remonta ya a algunas fuentes clásicas ${ }^{25}$ y, en todo caso, aparece también en la General Estoria.

Igualmente coinciden ambos textos en el hecho de que la prisión de Dánae sea una torre, detalle que también aparecía ya en la compilación alfonsí y la Genealogía de Boccaccio y que se retomaría posteriormente en otras versiones españolas del mito ${ }^{26}$. Por otro lado, la supresión de las referencias al oráculo exime al autor de los tres romances (suponiendo, como parece probable, que este autor sea uno solo y el mismo) de continuar el ciclo más allá de la liberación de Andrómeda y de su promesa de matrimonio con Perseo: pues en la leyenda clásica la luctuosa predicción acaba cumpliéndose por una fatal casualidad algún tiempo después del regreso del héroe a la tierra de sus ancestros maternos ${ }^{27}$.

Otro aspecto destacable es cómo Timoneda afirma que Júpiter «convirtióse en grano de oro/ y en lluvia muy moderada», recogiendo y reformulando así la ambigua expresión del traductor («tornado lluuia ogranos de oro»).

Cabe señalar que todas las coincidencias que observamos entre el romance y el texto de Bustamante se encuentran ausentes en el texto original latino que supuestamente está traduciendo el santanderino: pues Ovidio inicia su relato in medias res, en pleno vuelo de Perseo sobre el desierto de Libia (tras haber decapitado a Medusa), y omite los antecedentes relacionados con los orígenes de Perseo (salvo precisamente las fugaces referencias a la filiación divina de Perseo y a la lluvia de oro $)^{28}$.

${ }^{24}$ Cruz de Castro, op. cit., p. 31.

${ }^{25}$ En efecto, lo encontramos en los Diálogos marinos de Luciano de Samósata, y más concretamente en el de Tritón y las nereidas. Cf. Luciano de Samósata (1992). Obras. Vol. IV, trad. y notas por José Luis Navarro González. Madrid: Gredos, Biblioteca Clásica.

${ }^{26}$ El detalle de la torre aparece también, por ejemplo, en las Anotaciones sobre Ovidio de Pedro Sánchez de Viana (manejamos ejemplar custodiado en la Biblioteca Histórica de la Universidad de Valencia bajo la signatura Z-5/o83), donde leemos que Acrisio «edifico vna torre fortissima, en la qual encerro a su hija recien nascida, con el ama que la daua leche, poniendo personas (de las quales se fiaua mucho) para su guarda» (anotación 46, fol. 96). En realidad, entre las fuentes antiguas también esta versión es mayoritaria, aunque algunos autores, como Apolodoro o Higinio, hablan de una cámara subterránea de bronce edificada ex profeso para que sirviera como prisión de Dánae.

${ }^{27}$ Aunque, ciertamente, no en las Metamorfosis de Ovidio; y tampoco en la versión castellana de Bustamante, pese a que este trabajo supone una adaptación libérrima del poema latino, que incorpora elementos de muchas otras fuentes. El cumplimiento del oráculo consistirá en que Perseo hiera mortalmente a su abuelo al impactarle a este en un pie el disco que el joven había lanzado durane el transcurso de unos juegos que Acrisio había organizado para celebrar la reconciliación entre ambos.

${ }^{28}$ La narración de los hechos relativos a Perseo en las Metamorfosis ovidianas se extiende entre el Libro IV,v. 607 y el Libro V, v. 249. Por otro lado, Bustamante sí abre su relato sobre Perseo con una introducción - aunque breve, inexacta e incompleta- sobre el linaje humano del héroe; introducción que, como en el texto ovidiano, enlaza con la fábula anterior: «[Baco] era adorado como a dios y en toda lo [sic] tierra de Acaya todos 
Por otro lado, no dejamos de encontrar igualmente notables diferencias entre ambos textos; diferencias que podemos achacar al afán de Timoneda por recrear la materia mitológica, y que son las siguientes:

1. La ausencia en Timoneda de las alusiones de Bustamante a la «magestad» de Júpiter, quien se despoja de ella para irrumpir en el aposento de Dánae y regresa al cielo tras la desfloración de la muchacha.

2. La supresión por el romancista del detalle de la grieta en el techo aprovechada por Júpiter para infiltrarse en la alcoba (un motivo que también aparece en Alfonso X).

3. La introducción del episodio en el que la doncella recoge en sus faldas los granos de la lluvia de oro. En este pasaje, Timoneda parece hacerse eco de las interpretaciones que hacen hincapié en el valor que Dánae concede a la materialidad del precioso metal, y que la convertirían en prototipo del amor venalis ${ }^{29}$.

4. El desarrollo por Timoneda (aunque breve) del relato de la seducción de Dánae. Pese a lo que venimos diciendo, el romancista no convierte el regocijo inicial de esta por la lluvia de oro en una entrega interesada a Júpiter a cambio de riquezas ${ }^{30}$. Al contrario, el abandono de su divino amante la deja llena de desazón.

Un aspecto menor que podemos considerar en el texto romancístico sería la conversión del nombre de Acrisio en Acricio, conversión que no se da en ninguna de las dos ediciones manejadas de la traducción de Bustamante. En cambio, en ambas encontramos la forma Acrisis pocas líneas más abajo, en un pasaje que también será tenido en cuenta por Timoneda para su siguiente romance, el de Perseo. Sin embargo, en este segundo poema se mantiene la forma Acricio para el nombre del padre de Dánae, como veremos a continuación.

Pasando al segundo de los romances recogidos por Timoneda, a pesar del título (Romance de Perseo) constituye una continuación directa del anterior. Hasta tal punto esto es así que, si el final del Romance de Dánae se correspondía con una frase de Bustamante dejada a mitad, el de Perseo arranca precisamente con la continuación de ese mismo pasaje del cántabro. Podemos comprobarlo si, de nuevo, comparamos ambos textos:

le hazian una gran honrra sino Acrisio que no queria que entrase en su ciudad [...]. Este Acrisio era del linaje de cadmo y padre de Danae la qual despues pario a Perseo hijo de Jupiter y fue de la manera que ahora oyreis».

${ }^{29}$ Sobre esta cuestión, véase un panorama cronológico de obras y autores clásicos y modernos en Traver Vera, Ángel Jacinto (1996): «El mito de Dánae: interpretación y tratamiento poético desde los orígenes grecolatinos hasta los Siglos de Oro en España», Madrid, Cuadernos de Filología Clásica. Estudios latinos, n. ${ }^{\circ} 11$. Servicio de Publicaciones UCM. http://hispana.mcu.es/es/registros/registro.cmd?tipoRegistro=MTD\&idBib=264100

${ }^{30}$ En este sentido, no creemos que la mención de Timoneda a los «regalos» de Júpiter en el v. 21 haga alusión a un referente material, sino más bien a las caricias y buenas palabras con que el dios consigue seducir a la muchacha. 


\section{ROMANCE DE PERSEO}

Disimulando Dánae

su tristeza y su cuidado, y lo que Júpiter hizo, juntamente su preñado, no pudo celarlo tanto que Acricio, su padre honrado, no lo hubiese de saber, do en saberlo, muy airado, determinó de matarla; pero después, acordado, aguardó que ella pariese, y parió un hijo llamado Perseo, y a él y a ella (de mancilla rodeado) en una nave los puso, solos, sin ningún criado, a las olas y a los vientos los ofreciera de grado. La hermosa Dánae, viendo lo que el padre había obrado, y que la nave sin guía guiaba el viento doblado, y que sin mantenimiento iba, que era mal doblado, a Perseo tomó en brazos, este llanto ha comenzado: -Júpiter, di, ¿dónde estás? Di, ¿por qué me has olvidado? A lo menos este hijo tuyo, y mío, tan amado, te apiades que no muera, pudiendo ser remediado, y a Bóreas y a Neptuno mándales por tu mandado que esta nave surja en puerto salva, como he deseado. Con estas quejosas voces de sueño se han rodeado Dánae y Perseo juntos, y en un momento han llegado

a la ínsula de Acaya, del rey Polidete estado. El rey vino a ver la nave que en su puerto había aportado,

\section{VERSIÓN DE BUSTAMANTE}

[...] mas dissimulo su tristeza quanto pudo; pero no lo pudo encubrir tanto que al fin el padre lo vuo de venir a saber; el qual lleno de arrebatada yra la quiso

$5 \quad$ luego matar; mas despues no selo sufriendo el coraçon hazer acordo de dexarla hasta que pariesse para hazerla despues junto conel hijo morir muy cruda y desesperadamente por poderse vengar del demasiado enojo que contra ella tenia. Venido el tiempo del parto Danae pario vn niño a quien puso por nombre Perseo; el qual viendo su abuelo Acrisis tan lindo y agraciado mudo el proposito de matarle

15 luego; y acordo a el y a su madre dar otra pena menos graue y aspera; y fue que los metio en vna nao, y dexo los ambos solos sin ningun otro gouierno, ofreciendolos en poder de los brauos vientos y olas; la 20 nao vacilando ahora a esta parte ahora a aquella andaua; y la afligida dueña dentro siempre pidiendo ayuda y fauor a Jupiter; al qual plugo ahora con buen tiempo ahora con tempestad traerla ala insula de Acaya endonde biuia el Rey Polidete el qual en llegando al puerto los saco dela nao; y porque el era mancebo sin muger acordo tomar por amiga a Danae y a Perseo por hijo [...] 
45 y en ver a Dánae fue preso

de sus amores, llagado.

Y por ser el rey mancebo por amiga la ha tomado, y a Perseo, que es su hijo por su reino ha divulgado.
45

50

Como podemos observar, y al igual que ocurría con el Romance de Dánae, encontramos claras concomitancias entre el texto de Timoneda y el de Bustamante que manifiestan la dependencia de los romances respecto a la traducción ovidiana del cántabro.

El motor del abandono de Dánae y Perseo continúa siendo el afán de restaurar el honor de la familia, idea que el autor subraya de forma insistente en la primera parte del poema («su padre honrado», v. 6; «de mancilla rodeado», v. 14). Cruz de Castro señala la filiación folklórica del episodio — que en realidad forma parte del relato clásico de nuestro mito ${ }^{31}$ -

De acuerdo con este viraje de la historia se interpreta el motivo folklórico del héroe abandonado sobre las aguas, esto es, el tema de la expulsión del héroe por temor a la competencia, envidia o castigo (que aparece en todas las Mitologías, en la Biblia y en los cuentos populares del mundo entero). Se contempla en el romance como castigo de una afrenta. ${ }^{32}$

Curiosamente, y a diferencia de lo que ocurre en la fuente ovidiana ${ }^{33}$, el romance no nos indica que Acrisio - a quien, por lo demás, el autor continúa llamando Acricio, v. 6se niegue a creer en la filiación divina de su nieto; antes bien nos da a entender lo contrario, sin que ello sea óbice para que el padre de Dánae se sienta afrentado.

Por otro lado, y a diferencia de la versión de Bustamante (y del poema original latino), nuestro romance presenta ecos de un célebre fragmento de Simónides de Ceos (fr. 543 en Dion. Hal. $\pi$. ouv $\theta$. 221-224) en el que Dánae, a bordo de la barca a la deriva - junto al pequeño Perseo-, entona una canción de cuna que es a la vez un lamento por su situación ${ }^{34}$. Esta súplica de Dánae a Júpiter (que en el v. 33 incluye alusiones a otras divinidades como Bóreas y Neptuno, a las que Dánae espera que Júpiter envíe en su ayuda) se omite asimis-

31 Ya hemos hecho referencia a la filiación de la historia de Perseo con el cuento popular, según afirmaba Kirk.

32 Cruz de Castro, Marichu, op. cit., p. 31.

${ }^{33}$ Metamorfosis, Libro IV, v. 610. Cf. Ovidio Nasón, Publio (2002): Metamorfosis, I. Texto revisado por A. Ruiz de Elvira. Vol. I (Lib. I-IV), 1. reimpresión a la 5. edición. Madrid, CSIC. Alma Mater, Colección de autores griegos y latinos (la $1^{a}$ ed. data de 1964). http://es.scribd.com/doc/36049224/Ovidio-Metamorfosis-bilingue\#scribd

${ }^{34}$ El texto completo (en una versión española en forma de silva) es el siguiente: «Cuando, en el arca fina, sintió el soplo/ del viento y la corriente/ del mar revuelto, a Dánae/ le entró miedo y, con las mejillas húmedas,/ se echó sobre Perseo y, abrazándolo,/ dijo: «iQué pena tengo,/ hijo! Pero tu sueño no se turba,/ y duermes, no pensando/ sino en mamar, en este leño triste/ claveteado de cobre, que en la noche/ reluce, y donde sólo/ la oscuridad azul/ te arropa. No te importan/ ni el agua que te pasa por encima/ sin tocarte el cabello, ni el bufido/ del viento: siempre apoyas/ la hermosa cabecita en la frazada./ Si te espantara lo que te causa espanto,/ ya habrías dado oído a mis palabras./ Quiero que duermas, niño;/Y que se duerma el mar, que al fin se duerma/ esa aflicción inacabable. ¡Que haya/ un cambio, padre, Zeus,/ por tu merced! ¡Ay, si cualquier palabra/ injusta o temeraria hubiese dicho/ al suplicarte, perdónamelo!».(Texto procedente de Líricos griegos arcaicos, ed. de Juan Ferraté. Barcelona, Seix Barral, 1968, fragm. 21). 
mo en la práctica totalidad de las obras literarias españolas que recrean el mito de Perseo, lo que contribuye a la peculiaridad de este poema compuesto (o recopilado) por el editor valenciano, así como al misterio que envuelve su origen.

Otra aparente innovación de Timoneda sería el doble prodigio que sigue a la plegaria de Dánae y que sin duda debe interpretarse como la — sobrenatural— respuesta de Júpiter a la misma: el profundo sueño que se apodera de madre e hijo y la aceleración del tiempo, que convierte en inmediata la llegada de ambos a Acaya.

Precisamente esta identificación de Acaya con el lugar de la salvación de Dánae y el pequeño Perseo supone una notable coincidencia entre los textos de Timoneda y Bustamante; y supone, a su vez, una discrepancia con las versiones anteriores del mito (no literarias) en castellano. En efecto, el relato alfonsí localiza el rescate de Dánae «en las costas de Italia»; imprecisión que hallamos igualmente en el texto de Santillana. Por su parte, el Tostado sitúa el episodio en Apulia, como también hará más tarde Baltasar de Vitoria en su Theatro de los dioses de la Gentilidad (Salamanca, 1620).

La denominación como Acaya de la nueva patria de Dánae y Perseo sería incorporada por Lope y Calderón a sus respectivas comedias sobre el mito. Sin embargo, la fuente original ovidiana, que nada nos dice al inicio del relato sobre Perseo del lugar en el que este se ha criado, sí que se hace referencia a él cuando, al final de la narración, el héroe regresa para vengar el intento de seducción de Dánae por Polidectes: y según Ovidio, este lugar no es Acaya sino la pequeña isla de Sérifos. Observamos, pues, que las discrepancias e innovaciones onomásticas entre los diversos autores constituyen un fenómeno temprano en las versiones de un mismo mito clásico.

Novedoso es igualmente el tratamiento del personaje de Polidetes, ya que no solo es él quien encuentra la embarcación —en lugar de su hermano Dictis—, sino que su enamoramiento por Dánae se produce a primera vista en el momento de la arribada de esta; y asimismo es también él y no Dictis ${ }^{35}$ quien acoge a ambos: a la muchacha como su «amiga»y al niño Perseo presentándolo como propio ${ }^{36}$.

Estas circunstancias resultarán determinantes para la supresión, en esta versión del mito llevada a cabo por Timoneda, de diversos acontecimientos importantes: por un lado el episodio de Medusa, y por otro los sucesos posteriores a la unión matrimonial entre Perseo y Andrómeda. En efecto, las fuentes clásicas no nos presentan a Polidetes sino mucho más tarde, cuando ya Perseo es un aguerrido joven. En ellas, además, el rey es un personaje tiránico y hostil a Perseo que sufre una insana pasión por Dánae — no correspondida- que solo la presencia del hijo de esta le impide satisfacer por la fuerza. De ahí que, a la primera ocasión, envíe al muchacho a decapitar a la gorgona, con el fin de alejarlo de sus dominios

\footnotetext{
35 En el Tostado, Dánae y Perseo son recogidos por un pastor innominado.

${ }^{36}$ En cambio, el relato alfonsí nos presenta un matrimonio legítimo entre Dánae y el rey del lugar, que la convertirá en su reina: «Et aquel rey al qui la enpresento el pescador pues que sopo el fecho de la duenna $e$ el linnage dont uenie $e$ del ninnuelo cuyo fijo era, dio luego el ninno a criar $e$ mandol guardar muy bien, et tomo a Dane $e$ caso con ella. Et fallosse el rey muy bien daquel casamiento, $e$ salio ella muy buena duenna $e$ de buena uida $e$ prouo por buena reyna». (Alfonso x El Sabio (1957): General Estoria. Segunda Parte, I. Ed. de +Alfonso Solalinde/ Lloyd A. Kasten/ Víctor R. B. Oelschläger. Madrid: CSIC, Instituto «Miguel de Cervantes», Cap. CLVIII).
} 
—enviándolo a una muerte más que probable - y así lograr sus deshonestos propósitos. La solución ideada por Timoneda para evitar — por razones que en principio se nos escapanel relato de la primera y mayor hazaña del héroe facilita igualmente el silencio sobre la venganza que en las fuentes clásicas toma Perseo, a su regreso, contra Polidetes; pues este había intentado efectivamente forzar a Dánae durante la ausencia del joven ${ }^{37}$.

Por último, en las Rosas de Timoneda encontramos también un Romance de Andrómeda con el que parece concluir el ciclo de los poemas dedicados a nuestro mito. Sin embargo, la supresión del episodio relativo a Medusa no deja de conllevar diversas repercusiones en este romance final, pues el autor introduce en él diversos cambios que resultan ciertamente significativos. Así podemos comprobarlo si, de nuevo, comparamos el poema de Timoneda con el fragmento correspondiente de la versión ovidiana:

\section{ROMANCE DE ANDRÓMEDA}

Andrómeda está llorando que es gran lástima escuchar, la hija de Calíope, doncella hermosa sin par,
5

10

desnuda a una peña atada

junto a la orilla del mar,

las manos atrás liadas,

los pies sin los menear, los cabellos rubios sueltos

que no cesan de volar;

a los sollozos que daba

Perseo fuera a llegar,

viéndola de tal manera

que era lástima mirar,

5 y de otra parte alegría de tal figura gozar,

\section{VERSIÓN DE BUSTAMANTE}

Otro día amanescido Perseo ligo sus alas en sus pies y començo de bolar y veya muchas tierras debaxo desy; y entre las otras llego ala region delas tierras del rey çerfeo y vio entre vnas peñas cerca del mar donde estaua desnu-

$5 \quad d a$ y ligada de pies y manos andromeda por el pecado de su madre. Esta era hija del rey çerfeo; Jupiter la mando poner alli por la soberuia de su madre Caliope. Despues que Perseo vio la dama ligada entre vnas peñas donde el viento mouia sus cabellos; viendola tan hermosa llo-

10 rando penso que era ymagen de diuina diosa y luego fue enamorado della a tanto que no podia bolar a otra parte; y estandola assi mirando dixo. esta donzella no merescio porque estuuiesse aqui ligada; y llegandose a ella le dize. Hermana dime tu nombre o de qual tierra eres; o porque 15 estas aqui ligada. Ella callo y no oso dezir nada; y queria cubrir su cara mas no podia que las manos tenia impedidas començo de temor y verguença a muy dolorosamente

${ }^{37}$ Acerca del padrastro de Perseo, Alfonso x asegura que se llama Phauno, mientras que el Tostado se refiere a él como Piluno, y Vitoria como «Pylumno, o Polydectes». Este último cita a Luciano como fuente del pasaje correspondiente. Por lo demás, como señala Grimal, los nombres mitológicos presentan en nuestra lengua diversas variantes, a diferencia de lo que ocurre en otros idiomas como el francés o el inglés, más fieles -al menos en lo que se refiere a la escritura - al original griego y/o latino (Grimal, Pierre (1986): Diccionario de mitología griega y romana, trad. de Francisco Payarols, Barcelona, Paidós (3. ${ }^{a}$ reimpresión de la 1. ${ }^{a}$ ed. castellana en Paidós, revisada por el autor, 1981). Por otra parte, la General Estoria mantiene hasta el final del relato las buenas relaciones entre Perseo y su padrastro, y hace que la decisión de matar a Medusa -convertida en una poderosa reina- parta del propio Perseo, quien desea hacer méritos ante su abuelo Acrisio. En todo caso, en el pasaje de Bustamante suprimido por el romancista, la raíz de la animadversión que su padrastro concibe hacia Perseo con el tiempo (y que se convertirá en el motor para enviarle a dar muerte a Medusa) se debe a un temor a que el joven le arrebate el reino. Este problema no existe en el relato alfonsí, donde encontramos que Phauno y Dánae conciben un hijo que se constituye en heredero del reino, sin contestación por parte de Perseo. 
dijo: - Doncella, tu hado no dejes de me contar. Ella de ver a Perseo

20 quisiérase cobijar; no pudiendo, de vergüenza diose muy recio a llorar. Perseo dijo: - Doncella, ved si te puedo librar

25 o por qué estás aquí puesta, cuéntamelo sin dudar. -Es la causa, caballero, (no te lo puedo negar) que mi madre, Calíope

30 por hermosa se estimar, a los marítimos dioses a todos fue a despreciar, los cuales, airados, fueron a Júpiter se quejar.

35 Júpiter de ello enojado en mí se quiso vengar, y me ha puesto en esta peña para me sacrificar porque las bestias marinas

40 me coman a mi pesar. En tanto que esto contaba, fue una gran bestia [a] asomar para Andrómeda comer, muy terrible, y de espantar;

45 Perseo púsose en medio, con ella fue a pelear, matóla con gran esfuerzo sin cobardía mostrar, y después a la doncella con amor fue a desligar, cobijárale su manto, ella se fue a arrodillar, Perseo de bien criado alzóla, fuela a abrazar.

55 Rogándole está, rogando con él se quiera casar; ella dichosa y contenta, fuéronse ambos a besar. llorar; y luego hablando mostro [sic] aquel que tanto la importunaua el nombre de su tierra y el suyo; y dixo mas que por el pecado de su madre Caliope estaua alli 20 ligada; y la causa fue dize porque mi madre teniendose por muy gran señora menospreciaua los dioses marinos; los quales ayrados desto se quexaron a Jupiter todos los dioses y nymfas marinas. Jupiter tambien enojado de oyrlo tomo a mi (aun sin culpa;) y me man-

25 do sacrificar y poner aqui como me ves ligada de pies y manos para que una bestia marina me coma. En tanto que ella lo contaua vna gran bestia venia por la mar haziendo espantable estruendo para comer aquella tan hermosa donzella. Y quando ella vio la bestia venir dio 30 grandes bozes significadoras de su gran temor y espanto. El padre y la madre vinieron alli llorando ambos muy afligidos; mas la madre era mas triste viendo que ella lo merescia y que por malos de sus peccados no la podian ayudar sino con solas lagrimas y sospiros. Per-

35 seo que bolaua sobre el mar les dixo. Essas lagrimas que vosotros echays no pueden traer prouecho a ninguno de vosotros nia vuestra hija; por tanto menester es que otro consejo tomeys; y sera que si vosotros la quisierdes dar a a mi por muger pues que soy hijo de Jupiter y el que trayo la cabeça de Medusa y el que tengo poder de bolar por el cielo yo conla ayuda de dios saluare la donzella y sereys mas honrados por mi que por quantos oy son; ni podeys tomar por yernos en vuestra tierra. El padre y la madre fueron luego muy contentos 45 con aquellas palabras y prometieronle que le darian la mitad del reyno en arras. Estando enesto he aqui por do venia la bestia marina tan grande como una nao a gran priesa hendiendo la mar para comer la donzella; y ya estaua muy cerca delas peñas. Quando Perseo la

50 vio para pelear con ella alçose sobre las nuues. Quando la bestia fiera vio la sombra del enel agua començo a bramar y echar el agua por la boca muy alto. Perseo andaua cercando la al derredor por el cielo bien como aguila; y vaxando sobre la bestia le metio el espada 55 por la diestra espalda hasta la empuñadura. La bestia quando se sintio mal herida començo con mucha pena a rebolcarse y meterse vnas vezes debaxo del agua y alçarse otras vezes sobre el pecho. Uiendo que Perseo no le daua espacio por que vnas vezes le daua por el vientre otras le daua por el grande lomo; otras por el costado; la bestia conlos muchos golpes echaua la sangre por la boca muy alto y ensangrentaua todas las 
las aguas. Las alas de perseo se yuan mojando; por cuya causa perseo ya no osaua tener los pies mas enel agua; y viendo alli cerca vna gran peña que estaua en medio del mar; entre tanto la sierpe tenia la cabeça so el agua Perseo se arrimo a aquella peña; y conla vna mano se tenia ala peña y conla otra golpeaua muy osada y fuertemente ala bestia. Las lagrimas y las oraciones subieron al cielo delos padres, de manera que los dioses aplacados dieron luego victoria a Perseo de que el padre y la madre vuieron gran gozo, y desligando luego a su hija recibieron muy bien a su hierno dizendo que aquel solo libro su casa y su hija de muerte [...]

Como podemos observar, el romancista omite toda alusión a la presencia de los padres de Andrómeda y, en consecuencia, el diálogo que Perseo mantiene con ellos. Al mismo tiempo, no encontramos en el poema la detallada descripción de la lucha entre Perseo y el monstruo marino que ofrece el texto de Bustamante (en este caso fiel al original ovidiano), y que Timoneda despacha escuetamente en apenas cuatro versos (45-48). Igualmente notable es la ausencia en el romance de las sandalias aladas que permiten al héroe volar: en lugar de eso, y aunque el poema no lo especifica, da la impresión de que Perseo está pasando a pie por el lugar del suplicio de Andrómeda.

Asimismo observamos que el romance finaliza con el beso entre ambos jóvenes tras la liberación de Andrómeda, sin que aparezca ya la escena en la que Perseo, para lavarse las manos en el mar, deja en la orilla la cabeza de Medusa que, al contacto con el coral, lo endurece. Podría considerarse como otra de las «transformaciones» omitidas por el romancista, aunque cierto es que la materia mitológica seleccionada para construir su relato concluye con anterioridad a este pasaje y, por tanto, no se trata sensu stricto de una supresión.

Por otro lado, no dejamos de hallar algunas coincidencias textuales entre ambas piezas, aunque, como en los casos anteriores, se trata de expresiones que no resultan particularmente elaboradas en cuanto al estilo literario. Mucho más curiosa y sugerente nos parece una última coincidencia entre uno y otro textos: y es que, en ellos, el nombre de Casiopea se cambia por el de Calíope (que en realidad es el de una de las musas). A este respecto, parece evidente la confusión con la forma Casíope, variante de Casiopea que en castellano ya encontrábamos en Alfonso X, pero que también aparece en el propio Ovidio ${ }^{38}$.

${ }^{38} \mathrm{El}$ error, que se da en la editio princeps del trabajo de Bustamante, ya no aparece en la otra edición que manejamos, impresa en 1664. Por otro lado, este cambio del nombre de Casiopea por la forma Calíope sería retomado por Lope de Vega en su poema La Andrómeda, lo que puede indicar que la confusión no resulta tan extraña. Lo más curioso es que este poema de Lope aparece incluido en el volumen La Filomena, que se publicó en 1621: el mismo año en el que también se editó su comedia El Perseo, cuya composición es en realidad anterior en una década. Es decir: Lope emplea correctamente el nombre de Casiopea en 1611-12 y diez años después se edita el texto correspondiente, mientras que al mismo tiempo aparece otra obra suya en la que se da sin corregir el nombre de Calíope. 
En todo caso, bien podría ser que la citada deturpación tuviera un origen anterior al propio Bustamante y se debiera a las fuentes por él empleadas para su traducción de las Metamorfosis. Sea como fuere, pensamos que la causa tal vez pudiera encontrarse en alguna lectura errónea debida a la «s» alta, que habría sido confundida con una «l»; un error que no parece atribuible a Timoneda, versado editor e impresor (aunque claro está que hasta al mejor escribiente se le puede deslizar un borrón).

En realidad, no es el de la madre de Andrómeda el único nombre propio que presenta particularidades en el romance, puesto que el de Cefeo adopta la forma Cerfeo (lo que sin duda también puede interpretarse como una simple errata).

Por otra parte, de los tres romances es este último el que acusa con mayor evidencia el carácter fragmentario de este género épico-lírico tan característico de nuestra historia literaria. Así, el relato se presenta in medias res («Andrómeda está llorando/ que es gran lástima escuchar», vv. 1-2) y sin ofrecernos pista alguna sobre la identidad de su protagonista femenina hasta los dos versos siguientes («la hija de Calíope,/ doncella hermosa sin par») - y, en realidad, no se nos dice quién es esta Calíope; pues la aposición no ofrece dudas de que su referente es Andrómeda, al ir encabezada por una alusión a su doncellez, incompatible con la maternidad de Calíope- Tampoco se nos presenta a Perseo, a quien ciertamente ya conocemos si hemos leído los dos romances anteriores, pero que aquí es ya adulto; lo que se deduce de la propia narración sin que el romancista intente vincular este poema a los dos anteriores mediante la indicación de que ha pasado el tiempo.

El fragmentarismo de esta composición queda subrayado, asimismo, por su final abierto, pues Timoneda sella con un beso entre Perseo y Andrómeda el compromiso entre ambos, pero la serie romancística queda al parecer truncada sin continuación. Así pues, nuestro poeta suprime del mito original el episodio del matrimonio entre la joven pareja; y, con este, el del banquete nupcial que acaba con la encarnizada lucha que contra Perseo entablará el personaje de Fineo (tío y antiguo prometido de Andrómeda, que tras la liberación de la joven por el héroe desafía a este por haberla desposado).

Como venimos diciendo, es este tercer romance el que presenta variantes más notables respecto al relato ovidiano, y tal circunstancia se encuentra estrechamente vinculada a la omisión del episodio de Medusa. En efecto, a dicha supresión se debe el hecho de que Perseo acuda sin más al llanto de Andrómeda; sin que se nos indique que lo hace surcando los aires y portando la cabeza de la gorgona, ni que se encuentre en otra tierra distinta de Acaya (aspectos que no omite Bustamante). Resulta llamativo que el romancista se preocupe escrupulosamente de expurgar todos los detalles de la traducción ovidiana que se refieren a estos hechos: pues no solo evita aludir al vuelo de Perseo, sino que, al suprimir las palabras que el héroe dirige a los padres de Andrómeda se elimina, al mismo tiempo, la referencia que en ellas hace a la decapitación de Medusa.

Además, y como ya queda dicho, en caso de que con este tercer poema se cierre efectivamente el ciclo romancístico de Perseo, el autor evita asimismo las bodas entre el héroe y Andrómeda; un episodio en el que, en la materia mitológica original, se encuentra muy presente la referencia a la gorgona: por un lado, en el relato que hace Perseo acerca del pasado de Medusa, por otro en la exhibición de su mortífera cabeza como arma definitiva contra 
Fineo y sus secuaces. En el mismo sentido, al cerrarse el ciclo con el primer beso entre Andrómeda y Perseo y la promesa de matrimonio entre ambos (un happy end aceptable dentro del paradigma caballeresco del gusto de la época de Timoneda), se evita narrar los hechos posteriores, en los que la cabeza de Medusa vuelve a cobrar protagonismo como arma letal.

De hecho, la motivación de Perseo para luchar contra la bestia marina y así salvar a Andrómeda es otra de las grandes diferencias de Timoneda respecto a la fuente ovidiana. En efecto, en el romance, el héroe lo hace de forma inmediata y espontánea al ver a la fiera dispuesta a devorar a la hermosa doncella y sin vincular su heroica acción a la condición de casarse con ella impuesta a sus padres. Además, estos no aparecen en el poema: se nombra a la madre de Andrómeda, pero nada se dice de Cefeo ni del hecho de que ambos son los reyes de Etiopía. La petición de mano se produce a posteriori y directamente a la muchacha, que reacciona «dichosa y contenta» (v. 57) a la propuesta de su salvador. El poema queda así recubierto de tintes románticos, lo que lo acerca a la corriente caballeresca.

Estas modificaciones respecto a la materia mitológica original contribuyen a una cierta «desmitificación del mito» al humanizar al héroe, que no cuenta con armas mágicas para liberar a Andrómeda, sino solo con su propio valor ${ }^{39}$; una humanidad que queda subrayada por el amor desinteresado que muestra hacia Andrómeda. Tal circunstancia parece ir aparejada con un intento del autor por asimilar la leyenda mitológica con el ideal caballeresco: una práctica frecuente en el romancero clásico, como señala Cruz de Castro en su «Nota preliminar»:

El espíritu caballeresco medieval, sus normas y sus hábitos, influye en los romances mitológicos compuestos con anterioridad al Romancero nuevo; el mito se narra en ellos como si se tratara de materia histórico-épica o carolingia [...]. El romancista aplica a los contenidos clásicos las técnicas literarias del momento sin reparar en la índole de lo narrado ni en la naturaleza de sus personajes: divinidades y héroes antiguos se confunden con caballeros medievales, todos son hombres del siglo xv. Esto significa una interpretación libre de lo mítico, un obviar la distancia del tiempo mediante retoques y aderezos cuyo resultado es la medievalización del mito clásico ${ }^{40}$.

A este respecto, no resulta casual el hecho de que Andrómeda se dirija a Perseo mediante el apelativo de «caballero» en el v. 27.

Sin embargo, no se puede hablar de una expurgación total de los elementos que identifican este romance con la temática mitológica, pues en él aparece con toda claridad la presencia de las divinidades paganas: por un lado los «marítimos dioses» (aunque el romancista omite la referencia a las «nynfas marinas» de las que sí habla Bustamante); por otro, el

39 En efecto, Timoneda omite en sus romances cualquier alusión a los objetos mágicos que en el poema latino le proporcionan a Perseo diversas divinidades; ausencia que contribuye a dotar al relato de cierta verosimilitud (si obviamos el episodio de la lluvia de oro) y a resaltar el valor del héroe como motor de sus hazañas. Estos objetos (proporcionados por las ninfas, gracias a su vez a las greas) son: el casco de invisibilidad de Plutón, las sandalias aladas de Mercurio y la égida de Minerva. Este último objeto actuará como un espejo que permitirá a Perseo dar muerte a la gorgona sin tener que mirar directamente su cabeza, que tenía el poder de petrificar a quien la mirase. Así pues, esos objetos cuya mención se omite en los romances guardan una relación directa con el episodio de Medusa (cuya cabeza funciona en el mito original como otro de los objetos mágicos enpleados por Perseo).

${ }^{40}$ Cruz de Castro, Marichu, loc. cit, pp. 5-6. 
propio Júpiter, que es quien ha decretado el sacrificio de Andrómeda. Pese a ello, sí que se elimina la alusión de Perseo a su condición de hijo de este mismo dios, elemento que contribuye a la humanización del héroe y subraya su valor y su virtud caballeresca (aunque claro es que esta eliminación de la filiación divina de Perseo solo se da en este tercer poema) ${ }^{41}$.

En la misma línea de «medievalización» del relato mitológico se encuentra otra supresión practicada en este ciclo romancístico respecto al mito grecolatino: la del oráculo que vaticinaba la muerte de Acrisio a manos del hijo de Dánae y que era la causa de la prisión de esta. En los romances de Timoneda, como ya se ha visto, el encierro tiene su origen en el afán de conservar la honra de la doncella. Por otro lado, esta preocupación de Acrisio aparece también en la traducción de Bustamante: pero lo cierto es que Ovidio tampoco explica en sus Metamorfosis las circunstancias exactas de la concepción de Perseo: se limita a indicar que Dánae fue fecundada por Júpiter en forma de lluvia de oro; pero silencia tanto las causas de su encierro como el cruel castigo infligido por su regio padre y el salvamento de la muchacha y del pequeño Perseo. Así pues, la versión de Bustamante contiene ya ciertos elementos ajenos a Ovidio que contribuyen a una cierta asimilación de la materia mitológica a los gustos medievales, aunque en un grado mucho menor que en los romances; pues el trabajo del santanderino pretende ser una traducción del poema ovidiano, por más que incorpore algunos elementos procedentes de otras fuentes.

Pese a todo, y como venimos diciendo, en nuestros romances la desmitificación y la consiguiente medievalización no son totales, pues Timoneda mantiene la filiación divina de Perseo y la existencia de otras deidades paganas. Tampoco parece totalmente lógico, dentro de los esquemas del romancero, obviar la sangre real de Acrisio — por tanto de Dánae- y de Andrómeda: solo Polidetes mantiene su condición de soberano de Acaya, circunstancia que el romancista no aprovecha para convertir a Dánae en su reina (como sí hace el narrador alfonsí), sino que solo la toma por «amiga».

Como podemos observar a la luz de nuestro análisis, estos primeros textos de la literatura española dedicados al mito de Perseo presentan numerosas modificaciones respecto a las fuentes originales de la Antigüedad. Las variantes incluyen cambios de nombres propios debidos, probablemente, al influjo de la traducción de las Metamorfosis hecha por Bustamante: así, los de algunos personajes - especialmente el de Casiopea, convertida en Calíope- o de topónimos como Sérifos - transformada en Acaya por el romancista-. Pero junto a estos, encontramos otros cambios mucho más profundos. Entre estos últimos, sin duda el más notable es la supresión de un episodio clave como la decapitación de Medusa; supresión que conlleva, a su vez, la de otros sucesos derivados de dicho episodio.

Por otro lado, no debemos olvidar que, posiblemente, los romances que comentamos no se deban a la autoría de Timoneda, quien podría haberse limitado a recopilarlos. En todo caso, lo que parece fuera de dudas es que estos tres poemas son obra de un autor que no carece de cierta cultura (o al menos muestra cierta voluntad de estilo, como sugiere el uso de

${ }^{41}$ Cabe matizar que el elemento maravilloso no deja de estar también presente en la narrativa caballeresca. Por otro lado, en la comedia de Lope sobre el mito de Perseo el episodio de la decapitación de Medusa queda reelaborado mediante una serie de elementos alegóricos que lo acercan también al mundo caballeresco, sin que pare ello sea óbice la presencia de la cabeza de la gorgona en el desarrollo ulterior de la obra. 
la rima consomante) y que se basa fundamentalmente en la traducción en prosa de las $\mathrm{Me}$ tamorfosis ovidianas llevada a cabo por Jorge de Bustamante. Por lo demás, la omisión del episodio de Medusa queda sin explicar y en nuestra opinión es deliberada, pues los restantes acontecimientos narrados aparecen perfectamente trabados entre sí y resultan coherentes con tal ausencia. Por tanto, parece descartada la posibilidad de que se hubiera perdido un supuesto romance intermedio sobre la decapitación de la gorgona (y otro sobre Atlas).

En cuanto a las fuentes, además de la traducción de Bustamante nos parecen dignos de mención los ecos de Simónides (bien que lejanos) en la plegaria en la que Dánae implora la ayuda de Júpiter durante su travesía a bordo del arca. Un influjo que no resulta nada habitual en los textos castellanos que adaptaron el mito de Perseo, y que sorprendentemente hallamos en estos poemas que lo recrean por primera vez en la historia de nuestra literatura. 
